\section{Um novo paradigma para o tratamento do câncer}

Durante anos, os oncologistas emprestaram para a abordagem de tumores sólidos paradigmas de tratamento oriundos dos sucessos obtidos na cura de leucemias de adultos e crianças. Para que se atingisse a cura, necessário seria induzir uma resposta completa com a erradicação de toda a evidência clínica, imagenológica ou laboratorial do tumor. Para a consecução desta meta primordial, segundo este paradigma, valeriam a pena sacrifícios enormes como toxicidade exacerbada e inclusive uma fração de mortalidade associada ou tratamento. Sob este modelo de tratamento, drogas quimioterápicas com diferentes mecanismos de ação seriam associadas em regimes poliquimioterápicos que deveriam ser administrados por vários ciclos, mesmo após a erradicação de todo o tumor.

Entretanto, a incurabilidade quase que universal de tumores sólidos metastáticos como os de mama, pulmão, próstata e do trato digestivo, mesmo com a administração de regimes poliquimioterápicos em doses plenas e até em doses supraconvencionais, abalou o paradigma vigente. Concluiu-se que a quimioterapia só poderia curar em estádios avançados tumores de alta quimiossensibilidade como os tumores germinativos, linfomas e leucemias. Entretanto, para os demais tumores sólidos metastáticos, ainda que estas neoplasias gozassem de quimiossensibilidade discreta durante parte de sua evolução natural, a quimioterapia isoladamente, com as drogas que possuímos no momento, não é curativa. Restam duas alternativas: I) a pesquisa de novas drogas que possam melhorar ainda mais os resultados hoje obtidos com os esquemas poliquimioterápicos vigentes e 2) quebrar o paradigma atual.

Em 1995, Takahashi' propunha que muitas vezes o maior ganho para o paciente com um tumor incurável adviria de uma fase prolongada de citostase, de estabilidade do contingente de lesões tumorais, ainda que estas não tivessem uma redução significativa de seus tamanhos. Ou seja, mesmo sem uma resposta tumoral objetiva, poderíamos prolongar e aumentar a qualidade da vida de nossos pacientes. Esquemas de poliquimioterapia ou monoquimioterápicos pouco tóxi$\cos$, hormonioterapia e mais recentemente anticorpos monoclonais e pequenas moléculas, como é o caso do Gefinitib (Iressa ${ }^{\circledR}$ ) e o Imatinib (Glevec $\left.{ }^{\circledR}\right)$, que interferem diretamente com visas essenciais para a manutenção do crescimento tumoral, se adequam perfeitamente a este novo paradigma de controle prolongado de tumores incuráveis, com toxicidade aceitável e pouca interferência com a qualidade de vida de pacientes com câncer.

Como integramos esta nova maneira de tratar tumores sólidos em nossa rotina? Primeiramente, reformulando nosso critério de resposta tumoral, isto é, migrando de um modelo onde apenas uma resposta objetiva é valorizada para um outro, onde o período de tempo sem que haja progressão tumoral passe a ser o objetivo procurado. Desta forma, não descartaremos alternativas terapêuticas extremamente úteis, porém ineficazes se julgadas por critérios de resposta mais antigos. Em segundo lugar, devemos entender que o câncer pode se converter em uma doença crônica como é hoje o diabetes, a hipertensão arterial, a hipercolesterolemia, etc. Como não curamos estas enfermidades e apenas as controlamos, nós, médicos, e os pacientes por elas acometidos não entendemos esta situação de "incurabilidade" como um fracasso. Entendemos este cenário como uma oportunidade para um controle prolongado destas enfermidades com a menor interferência possível nas vidas destes enfermos. Talvez, em um futuro próxi mo, o câncer poderá se tornar mais um dos problemas na história clínica de nossos pacientes e não o seu determinante.

\section{Auro del Giglio São Paulo - SP}

Referência

Takahashi Y, Nishioka K. Survival without tumor shrinkage: re-evaluation of survivalgain by cytostatic effect of chemotherapy. J Natl Cancer Inst 1995; 87: 1262-3.

\section{Bioética e vulnerabilidade: o médico e o paciente}

As reflexões bioéticas são abrangentes e devem sempre abordar todos os ângulos dos assuntos em foco, sejam eles de características mais emergentes, por conseguinte mais empolgantes, sejam eles mais tra dicionais, portanto mais conservadores. Quando se trata da vida cotidiana, os aspectos emergentes e empolgantes cedem lugar a aspectos mais tradicionais e conservadores, mas nem por isso menos importantes ou que deixem de se constituir em dilemas a serem analisados.

O desenvolvimento dos conhecimentos científicos permitiu a aquisição de novas posturas em relação a inúmeros ângulos do comportamento entre os participantes da área de saúde. Como conseqüência ou produto dessas variações e com a introdução de análises baseadas em diversos e diferentes setores do pensamento humano, como a abordagem da doutrina bioética, a área de saúde se viu invadida por personagens cuja prioridade não é igual à preocupação dos profissionais formados nos conhecimentos teóricos e práticos das ciências da saúde. Assim, muitos aspectos do modo de agir do médico passaram a ser passíveis de discussão.

Apesar de muitos terem posições marcadas por dogmas, considerados, portanto, imutáveis, o passar do tempo com o advento de invenções e descobertas, levou o posicionamento ético a se modificar, ainda que muitas vezes sem que houvesse uma percepção acentuada. Isso se realça com a dificuldade que se tem de observar as ocorrências da rotina diária.

É sempre de hábito em cada situação considerar que a evolução do seu tempo é sempre mais rápida e mais profunda do que em tempos anteriores. Com isso, cada novidade traz a atenção para o novo, negligenciando-se - que ocorre no transcorrer da rotina diária. Como o novo é o emergente que modifica a rotina a vida cotidiana, mais conservadora e menos atraente tem dificuldades de receber atenção e muito mais ainda, com essa falta de atenção, receber uma contribuição para seu aperfeiçoamento e melhoria. A vida na Terra transformou-se em espinhosa à observação, contraditória em relação ao progresso das ciências e conflitante para quem distingue moral pregada e moral praticada!. A relação do médico com o seu paciente, antiga e tradicional rotina que ocorre todos os dias vem vivendo esses dilemas.

O desenvolvimento das tecnologias, a complexidade das aparelhagens, a dificuldade em ter o conhecimento dos seus manejos e o 
tempo necessário para adquirir a capacitação de como aplicá-los corretamente no que seja necessário, estabeleceram uma distância entre o médico e o seu paciente que vai aumentando quanto mais especializada é a capacitação do profissional. Muitas vezes escondido atrás da sua aparelhagem, o médico não se apresenta ao paciente.

$\mathrm{Na}$ realidade, a relação entre o médico e o seu paciente se faz por um processo de interação social, o qual ocorre dentro da sociedade através de um sistema que define o papel dos participantes, especifica o padrão de comportamento e fornece um conjunto de valores e orientação, em termos dos quais os membros interatuantes são motivados para ação. O êxito dessa situação interativa traduz-se na eficiência da atenção médica e está diretamente relacionado com as atividades, valores, conhecimentos e expectativas dos participantes. Isso porque, apesar de leiga nos aspectos científicos da saúde, a população não é passiva e completamente receptiva às determinações médicas. Tem a popu lação seus próprios valores e seus padrões, que inúmeras vezes, mesmo não atendendo o que, seria desejável em uma análise racional ditada pelos conhecimentos técnicos científicos da medicina, são por ela, população, reconhecidos como corretos e válidos ${ }^{2}$.

Esses valores e padrões sobre a saúde pertencentes à cultura é que são os determinantes da ação que leva ao início do contato médico-cliente. Esse início é sempre provocado pelo paciente que toma a decisão de procurar o facultativo. Essa decisão não é simples, não só pelo reconhecimento de ter sua saúde abalada, como também por razões econômicas, não só em termos monetários, como também pela perturbação em sua rotina de vida diária e pela preocupação que esse fato causa. O paciente, ele mesmo, tem dificuldade em decidir se está ou não doente, e neste último caso qual a atitude a ser toma$\mathrm{da}^{2}$. Deve decidir se precisa de auxílio e onde procurar essa ajuda. A compreensão da doença por parte do leigo não é correta em termos científicos, pois ela depende de fatores biológicos, psicológicos, educacionais, econômicos, sociais e culturais. Todavia, qualquer que seja a percepção da condição de doente, normalmente é a pessoa, futuro paciente, que faz o primeiro diagnóstico e quem decide para solucionar seu proble$\mathrm{ma}^{2}$. Acontece não com pouca freqüência que esse primeiro momento, início da relação médico-paciente, seja, pelo menos para o paciente, angustiante e desagra dável. Uma discussão procurando os direitos dos pacientes excluídos, forçando uma dura intervençãa ${ }^{3}$, não deve ter sucesso, pois o problema não é econômico, é cultural.

Essa situação do paciente quando se encontra em vias de decidir qual o caminho a ser escolhido à procura de alívio para o seu sofrimento, seja ele da monta que for, esbarra tão logo com as dificul dades que a sociedade estabelece para que a atenção médica possa ser oferecida. De pronto a barreira de não poder exercer o direito de escolha se levanta. Sem dúvida, a não ser para uma pequena parcela da sociedade, a liberdade de decidir livremente, dentro de limites plausíveis, como e a quem se dirigir para a solução de seus problemas em nível de atenção médica não está ao alcance. A sociedade, mesmo tendo a preocupação de universalizar a atenção à saúde e oferecer atendimento nos episódios de doença, não tem se organi zado para permitir que a decisão do paciente de escolher o médico que deseja possa ser realizada. Geralmente o paciente procura o médico que está ao seu alcance.

A sociedade é tolerante a essa situação, pois até os mais abnegados em procurar uma fórmula capaz de oferecer a possibilidade de escolher livremente o médico se defrontam com muitos e persistentes empecilhos. Não há dúvida de que não existe uma sociedade que possa de maneira justa oferecer a todos os seus cidadãos a mesma atenção à saúde. Por um princípio de justiça, tal fato deveria ocorrer. A relação oferta e demanda, de um lado a capacidade social de oferecer a atenção necessária e de outro a demanda cada vez mais exigente por essa atenção, em que a oferta é delimitada pela possibilidade econômica, enquanto a demanda é dependente dessa mesma oferta, não alcança um equilíbrio desejado. Em algumas ocasiões, a oferta de uma variante dessa relação se faz de modo inadequado. É o caso de quando a sociedade, ao oferecer uma quantidade de médicos acima do necessário, acirra a competição criando a comercialização da mão -de-obra. Como esse acréscimo não vem acompanhado de um mercado capacitado para absorvê-lo se produz uma injustiça com os novos profissionais. Na competição no mercado de trabalho, 0 profissional procura se especializar no novo, no empolgante, levando mais tempo para sua formação, onerando a sociedade e geralmente se afastando do cotidiano responsável pela maioria das necessidades de atenção. Na impossibilidade de fazer justiça, a sociedade se torna tolerante sem se preocupar em discutir essas dificuldades. Não se procura o melhor em relação aos valores humanos, mas sim o possível em termos econômicos. Suprime-se a ética se esquecendo a discussão.

Dentro dessa perspectiva, outros fatores, entretanto, acontecem produzindo uma maior deterioração na relação entre o médico e o paciente. Muitas vezes o médico procura em prazo pequeno atender um número maior de clientes, outras vezes em razão da falta de tempo ou de organização esquece algum paciente por longo tempo. Dependente de múltiplas atividades que pretende exercer ao mesmo tempo, não tem a preocupação com o horário estabelecido. Coloca-se nesses momentos acima do bem e do mal entendendo que ao paciente só resta esperar. Essa espera é agonizante. Agonia que passa a irritação, quando por razões várias, seja de amizade ou de compromissos financeiros, o médico discrimina na escolha de quem primeiro deve ser atendido. $\mathrm{O}$ paciente não vai à procura do médico por vontade própria, sequer para satisfazer um desejo, vai porque tem uma necessidade premente de socorro. Nessa ânsia pelo socorro e nessa espera pelo atendimento é que acontece o contato das duas partes. A solidariedade social da espera promulgada em gabinetes políticos, também, é evidenciada nos consultórios e ambulatórios médicos de todos os níveis.

Muitos dos que se dedicam às análises feitas através da doutrina bioética, ou que se dizem a elas se dedicarem, não têm a preocupação com os assuntos do cotidiano. Poucos procuram estudar o que acontece no dia-adia. Fundamentalmente o que ocorre no dia a 
dia é a relação do médico com seu paciente. Esse dilema bioético nada tem de atrativo na sua discussão pois seus imperativos morais se distanciam não só em relação aos interesses dos participantes como, também, daqueles que por ele poderiam estar interessados e para ele dar uma participação proveitosa. Os princípios bioéticos destinados à clínica dificilmente podem ser atendidos.

No contexto do dia-a-dia, é difícil imaginar um consentimento informado para um paciente autônomo, quando falta a esse paciente o primeiro de seus direitos, o de escolher o que melhor the convier para tratar de seus males. Impossibilitado, se vê também constrangido a se sujeitar à rotina no atendimento que, raras vezes, é seguida com a preocupação de verificar suas dificuldades. Nada resta senão concordar com o que the é oferecido. Não existe nessas situações a liberdade de optar pelo que deseja, a autonomia do paciente é abandonada ${ }^{4}$. Ao paciente nada mais resta que aceitar o que the é oferecido.

Ambas as partes, o médico e o paciente, são vulneráveis nessa relação. E a sociedade como um todo talvez seja a maior responsável, pois mesmo com o desejo de revolver esse dilema, até agora não conseguiu atingir o seu desiderato.

\section{Referências}

I. Berlinguer, G. Questões de Vida: ética, ciência, saúde. Londrina: APCE-HUCITEC-CEBES; 1993. 2. Meira AR. Relação médico- paciente. $O$ Estado de São Paulo, p.8, São Paulo, 28 jun 1976.

3. Garrafa V, Porto D. Bioética, poder e injustiça: por uma ética de intervenção. $O$ Mundo da Saúde 2002; 26(I):6-15.

4. Pessini L, Barchifontaine CP. Problemas atuais de Bioética. $4^{\circ}$ ed. São Paulo: Editora Loyola; 1997.

Affonso Renato Meira

Professor-Emérito da Faculdade de Medicina da Universidade São Paulo 